\title{
Reactive oxygen species induced by uric acid promote NRK-52E cell apoptosis through the NEK7-NLRP3 signaling pathway
}

\author{
DONGDONG LI ${ }^{1}$, LUOBING WANG ${ }^{1}$, JIAOYING OU ${ }^{2}$, CHUANXU WANG $^{1}$, \\ JIABAO ZHOU ${ }^{1}$, LILI LU ${ }^{1}$, YANSHNEG WU ${ }^{1}$ and JIANDONG GAO ${ }^{1}$ \\ ${ }^{1}$ Department of Nephrology, Shuguang Hospital Affiliated to Shanghai University of Traditional Chinese Medicine, \\ TCM Institute of Kidney Disease, Shanghai University of Traditional Chinese Medicine, Key Laboratory of \\ Liver and Kidney Diseases (Shanghai University of Traditional Chinese Medicine), Ministry of \\ Education, Shanghai Key Laboratory of Traditional Chinese Clinical Medicine, Shanghai 201203; \\ ${ }^{2}$ Department of Internal Medicine, Shanghai TCM-Integrated Hospital Affiliated to Shanghai University of \\ Traditional Chinese Medicine, Shanghai 200082, P.R. China
}

Received March 23, 2021; Accepted June 29, 2021

DOI: $10.3892 / \mathrm{mmr} .2021 .12368$

\begin{abstract}
Increasing uric acid (UA) could induce renal tubular epithelial cell (NRK-52E) injury. However, the specific mechanism by which UA induces renal tubular epithelial cell injury remains unknown. It was hypothesized that UA induces renal tubular epithelial cell injury through reactive oxygen species (ROS) and the Never in mitosis gene A (NIMA)-related kinase 7 (NEK7)/NLR family pyrin domain containing 3 (NLRP3) signaling pathway. TUNEL assay and flow cytometry were applied to measure apoptosis, and the results of the present study showed that UA treatment induced apoptosis of NRK-52E cells in a concentration-dependent manner. Western blotting was performed to determine the expression levels of cleaved caspase-3, Bax and Bcl-xl, it was found that levels were significantly increased after UA treatment in NRK-52E cells. ROS and apoptosis were predominantly induced in NRK-52E cells and there was an association between ROS and apoptosis. Enhanced expression of NEK7, NLRP3, apoptosis-associated speck-like and caspase-1 were observed in NRK-52E cells treated with UA. The ROS inhibitor, N-acetyl-l-cysteine, exerted a protective effect on the UA-induced apoptosis of tubular epithelial cells by reducing excess ROS production,
\end{abstract}

Correspondence to: Professor Jiandong Gao, Department of Nephrology, Shuguang Hospital Affiliated to Shanghai University of Traditional Chinese Medicine, TCM Institute of Kidney Disease, Shanghai University of Traditional Chinese Medicine, Key Laboratory of Liver and Kidney Diseases (Shanghai University of Traditional Chinese Medicine), Ministry of Education, Shanghai Key Laboratory of Traditional Chinese Clinical Medicine, 528 Zhangheng Road, Shanghai 201203, P.R. China

E- mail: gaojiandong@hotmail.com

Key words: reactive oxygen species, apoptosis, uric acid, never in mitosis gene A related kinase 7/NLR family pyrin domain containing 3 signaling pathway which significantly inhibited NEK7 and NLRP3 inflammasome activation. These results indicated that UA activates ROS and induces apoptosis of NRK-52E cells. The mechanism might be related to the regulation of the NEK7/NLRP3 signaling pathway.

\section{Introduction}

Long-term hyperuricemia leads to uric acid (UA) stone formation and irreversible kidney injury (1); however, the precise mechanism responsible for the development of UA-related kidney disease is still largely unknown. Serum uric acid is commonly elevated in subjects with chronic kidney disease (CKD). Recent evidence implied that an elevated UA level predicts the development of CKD and end-stage kidney disease (2). Therefore, it is necessary to determine the mechanism of UA-related kidney injury and develop novel and effective preventative strategies. Notably, apoptosis is widely considered as an important pathological process of UA-induced renal tubular epithelial cell injury (3). Therefore, understanding the underlying mechanism of apoptosis in UA-induced renal tubular cell injury is necessary. In recent years, there has been increased research on antiapoptotic therapy (4). Uric acid crystals and soluble UA can activate the immune system and increase the production of the reactive oxygen species (ROS), which can stimulate neutrophil chemotaxis and activate NLR family pyrin domain containing 3 (NLRP3) inflammasomes $(5,6)$. Never in mitosis gene A (NIMA)-related kinase 7 (NEK7) is a protein kinase that acts as a selective upstream regulator of NLRP3 inflammasome activation (7). Previous studies have revealed that NEK7 can connect the adjacent NLRP3 subunits and mediate NLRP3 inflammasome activation through mitotic interaction $(8,9)$. Currently, mitochondrial ROS is the most studied aspect of NLRP3 inflammasome activation and apoptosis $(10,11)$. Our previous study confirmed that UA could stimulate excess ROS production, which could further trigger the assembly of the NLRP3 inflammasome and induce renal tubular injury in 
hyperuricemic rats (12). NEK7 is required for NLRP3 activation via the direct NEK7-NLRP3 interaction (13). However, whether UA can induce renal tubular epithelial cell apoptosis by regulating ROS release and activating the NEK7-NLRP3 pathway remains to be elucidated. Therefore, the aim of the present study was to determine whether UA can induce ROS release and activation of NEK7-NLRP3 pathways to increase renal tubular epithelial cell apoptosis.

\section{Materials and methods}

Soluble uric acid preparation. In experiments requiring soluble uric acid, an appropriate amount of monosodium urate (MSU) crystals (cat. no. U2875 Sigma-Aldrich; Merck KGaA) were added into $1 \mathrm{M} \mathrm{NaOH}$ to a final concentration of $10 \mathrm{mg} / \mathrm{ml}$. The MSU crystals were then crushed using ultrasound and the solution was sterilized through $0.20 \mu \mathrm{m}$ filters. Crystals were not detected under polarizing microscopy (magnification, $\mathrm{x} 200$ ), nor did they develop during the experiments. The soluble uric acid solution was pre-warmed for $30 \mathrm{~min}$ at $37^{\circ} \mathrm{C}$ before use.

Cell culture and treatment. The normal renal tubular epithelial NRK-52E cell line was purchased from The Cell Bank of Type Culture Collection of The Chinese Academy of Sciences. Cells were cultured in high-glucose Dulbecco's modified Eagle's medium (DMEM; cat. no. C11995500BT; Gibco; Thermo Fisher Scientific, Inc.) supplemented with $10 \%$ fetal bovine serum (cat. no. 10099-141C; Gibco; Thermo Fisher Scientific, Inc.) and $1 \%$ penicillin and streptomycin (cat. no. C0222; Beyotime Institute of Biotechnology) at $37^{\circ} \mathrm{C}$ in a humidified incubator containing $5 \% \mathrm{CO}_{2}$ and $95 \% \mathrm{O}_{2}$.

When the adherent cells reached $80-90 \%$ confluence, they were passaged using $0.25 \%$ trypsin and $0.02 \%$ ethylenediaminetetraacetic acid (cat. no. C0201; Beyotime Institute of Biotechnology). The NRK-52E cells were cultured in 6-well polystyrene plates at $\sim 4 \times 10^{5}$ cells per well and treated using different concentrations of UA $(0,50$ and $100 \mu \mathrm{g} / \mathrm{ml})$ for $24 \mathrm{~h}$ to establish the cell injury model. Subsequently, cultured cells were divided into three groups: The control group, cells exposed to $100 \mu \mathrm{g} / \mathrm{ml}$ UA (model group) and cells pretreated with 20 mM N-acetyl-1-cysteine (NAC; cat. no. HY-B0215; MedChemExpress) and then treated with UA (the model plus NAC group). Apoptosis was detected using a terminal deoxynucleotidyl transferase nick-end-labeling (TUNEL) assay, western blotting and flow cytometry analysis. Triplicate wells per group were cultured for $24 \mathrm{~h}$ and the experiments were repeated three times.

Cell morphology. The NRK-52E cells were seeded in equal amounts $\left(4 \times 10^{5}\right.$ cells per well) into 6 -well plates and then exposed to UA $(0,50$ and $100 \mu \mathrm{g} / \mathrm{ml})$ for $24 \mathrm{~h}$. After the cell-drug interaction, the growth of NRK-52E cells in each group was observed under an inverted phase contrast microscope (Nikon Corporation) to investigate the morphological changes (magnification, $\mathrm{x} 400$ ).

Flow cytometry detection of cell apoptosis. Following treatment, the cells were counted and then resuspended in $100 \mu \mathrm{l}$ $1 \mathrm{X}$ binding buffer at a concentration of $1 \times 10^{6}$ cells $/ \mathrm{ml}$.
Subsequently, the cells in binding buffer were added to a $5 \mathrm{ml}$ culture tube, followed by gentle vortexing and incubation with $5 \mu$ l Annexin V-fluorescein isothiocyanate (FITC) and $5 \mu \mathrm{l}$ propidium iodide (PI) solution (cat. no. 556547; BD Pharmingen; BD Biosciences) for $15 \mathrm{~min}$ at room temperature in the dark. After adding $400 \mu 1 \mathrm{X}$ binding buffer to each tube, the apoptotic cell ratio was detected on a BD FACSCalibur flow cytometer (BD Biosciences) using FlowJo software (version 7.6.1; FlowJo LLC). Early apoptotic cells were differentiated by their unique characteristics of being Annexin $\mathrm{V}-F I T C^{+}$and $\mathrm{PI}^{-}$, and late apoptotic cells were counted as Annexin V-FITC ${ }^{+}$and $\mathrm{PI}^{+}$cells.

TUNEL assay. Apoptotic cells were measured using a One-step TUNEL Apoptosis Detection kit (cat. no. KGA7072; Nanjing KeyGen Biotech Co., Ltd.). Briefly, cultured cells were fixed with $4 \%$ formaldehyde at room temperature for $30 \mathrm{~min}$. Then, the cells were incubated with $1 \%$ Triton X-100. Subsequently, the cells were mixed with $50 \mu 1$ TUNEL reaction mixture containing biotin-11-dUTP and TdT Enzyme and then with streptavidin fluorescein at $37^{\circ} \mathrm{C}$ for $30 \mathrm{~min}$. The nucleus was counterstained using 4',6-diamidino-2-phenylindole at room temperature for $10 \mathrm{~min}$ in the dark. Slides were mounted using glycerol. Finally, apoptotic cells were examined using a fluorescence microscope under three fields of vision (magnification, x200; Nikon Eclipse 80i; Nikon Corporation).

Western blotting. The cells were grown to 80-90\% confluence, homogenized in ice-cold phenylmethylsulfonyl fluoride in radioimmunoprecipitation assay buffer (Beyotime Institute of Biotechnology) and incubated at $4^{\circ} \mathrm{C}$ for $30 \mathrm{~min}$. After centrifugation at 7,992 $\mathrm{x} \mathrm{g}$ for $15 \mathrm{~min}$ at $4^{\circ} \mathrm{C}$, the protein concentration of supernatant was measured using a bicinchoninic acid protein assay kit (Beyotime Institute of Biotechnology). The proteins $(40 \mu \mathrm{g})$ were electrophoresed on 6-10\% SDS-PAGE gels and then electrotransferred to a polyvinylidene fluoride membrane (EMD Millipore). The membranes were blocked for $1 \mathrm{~h}$ at room temperature using $5 \%$ skimmed milk powder (Beyotime Institute of Biotechnology) in phosphate buffered saline containing $0.1 \%$ Tween-20 (PBST), followed by probing with primary antibodies at $4^{\circ} \mathrm{C}$ overnight. Thereafter, the membranes were washed with PBST three times for $10 \mathrm{~min}$ each, followed by incubation with respective horseradish peroxidase-linked secondary antibodies at room temperature for $60 \mathrm{~min}$. Finally, ECL solution (cat. no. 180-5001W; Tanon Science and Technology Co., Ltd.) was applied to the membrane evenly before detection of the signals (T1600; Tanon Science and Technology Co., Ltd.). Quantitative analysis was performed using ImageJ software (v1.48; National Institutes of Health) The primary antibodies used were as follows: Rabbit anti-cleaved caspase-3 (cat. no. 9661; 1:1,000; Cell Signaling Technology, Inc.), rabbit anti-Bcl-xl (cat. no. ab32370; 1:1,000; Abcam), rabbit anti-Bax (cat. no. ab32503; 1:5,000; Abcam), rabbit anti-NEK7 (cat. no. ab133514; 1:5,000; Abcam), rabbit anti-pro-Caspase-1+ p10 + p12 (cat. no. ab179515; 1:1,000; Abcam), rabbit anti-NLRP3 (cat. no. 19771-1-AP; 1:1,000; ProteinTech Group, Inc.), mouse anti- $\beta$-actin (cat.no.66009-1-lg; 1:5,000; ProteinTech Group,Inc.) and rabbit anti-apoptosis-associated speck-like (ASC; cat. no. YT0365; 1:1,000; ImmunoWay Biotechnology Company). Horseradish 


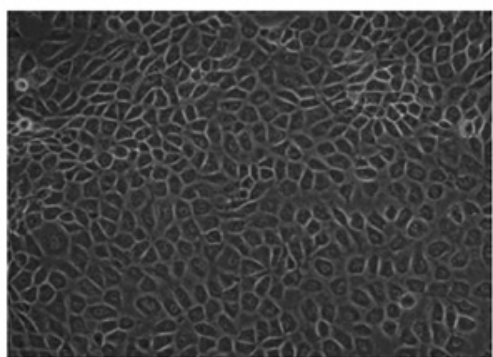

Control

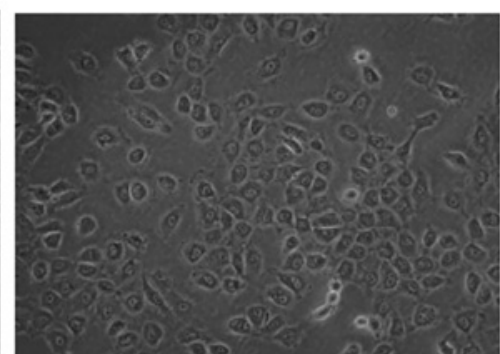

UA50

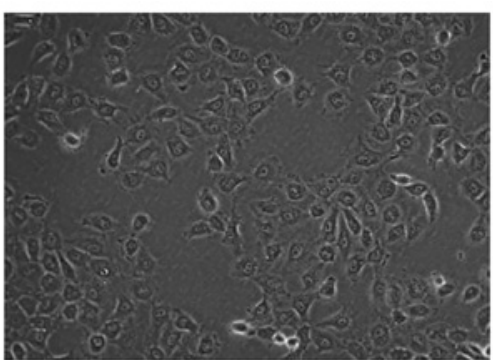

UA100

Figure 1. Morphological changes of NRK-52E cells after treatment with UA for 24 h. Magnification, x400. UA, uric acid.

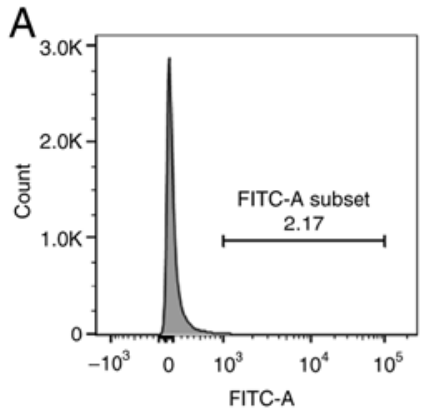

Control

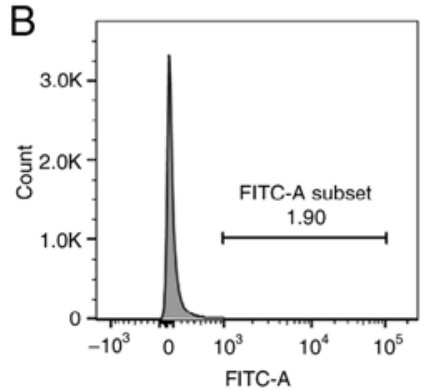

Control

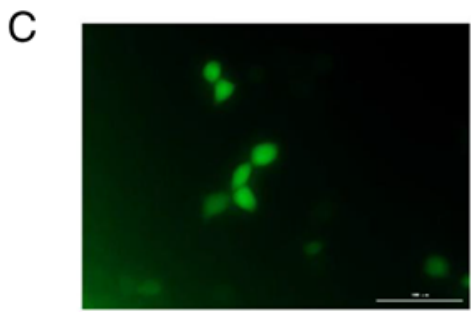

Control

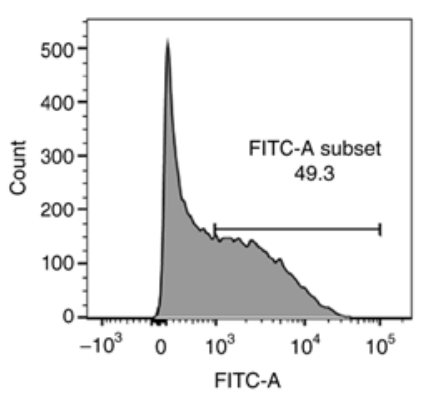

UA50

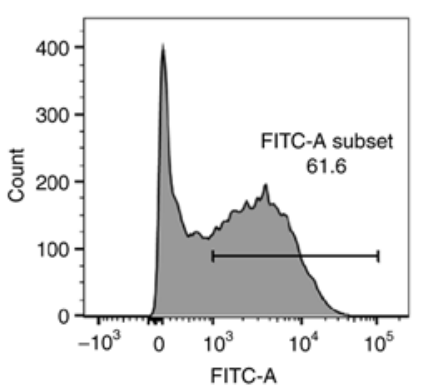

Model

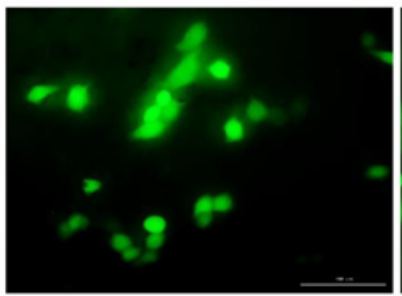

UA 50
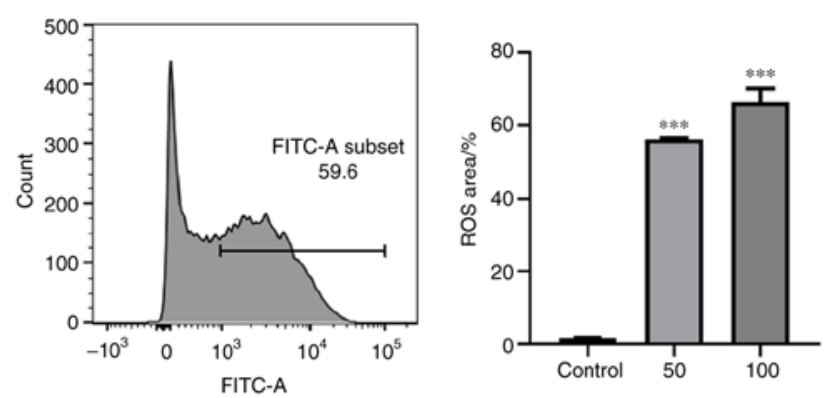

UA 100

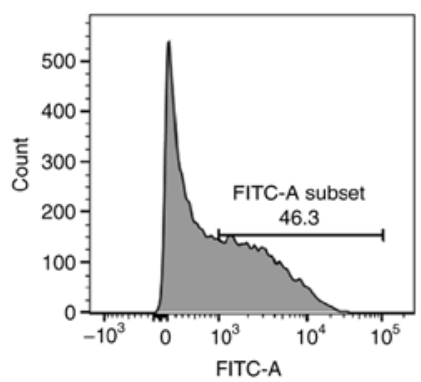

NAC

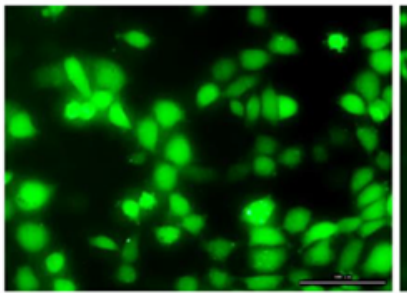

UA 100
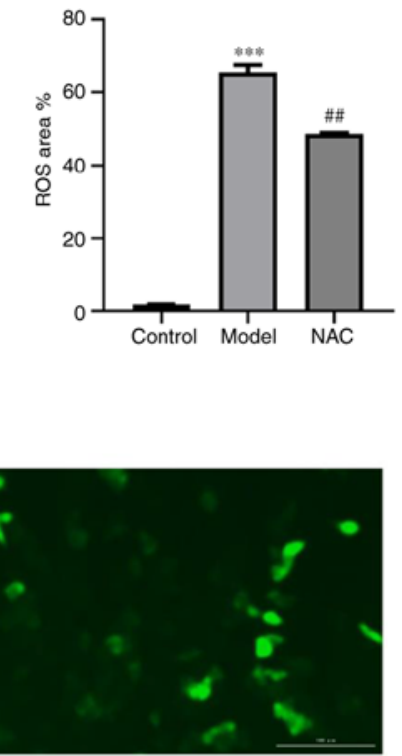

NAC

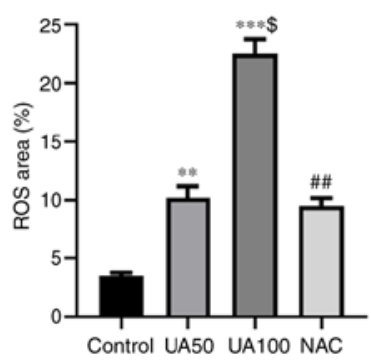

Figure 2. Effect of UA on ROS generation in injured NRK-52E cells. (A and B) Flow cytometry assays showing ROS production in NRK-52E cells treated with $0,50,100 \mu \mathrm{g} / \mathrm{ml}$ UA for $24 \mathrm{~h}$ and the percentage of ROS-producing cells. NRK-52E cells were pretreated with $20 \mathrm{mM}$ NAC for $1 \mathrm{~h}$ and then treated with UA for an additional $24 \mathrm{~h}$ and the percentage of ROS-producing cells was examined using flow cytometry. (C) DCFH-DA was used to measure the UA-induced cellular ROS (magnification, $\mathrm{x} 400$ ). $\mathrm{n}=4$ independent samples; data represent the mean \pm standard error of the mean. ${ }^{* *} \mathrm{P}<0.01,{ }^{* * *} \mathrm{P}<0.001$ vs. the control group; ${ }^{\$} \mathrm{P}<0.05$ vs. the UA50 group; ${ }^{\# \#} \mathrm{P}<0.01$ vs. the model group. UA, uric acid; ROS, reactive oxygen species; NAC, N-acetyl-1-cysteine; DCFH-DA, 2',7'-dichlorofluorescin diacetate. 
A
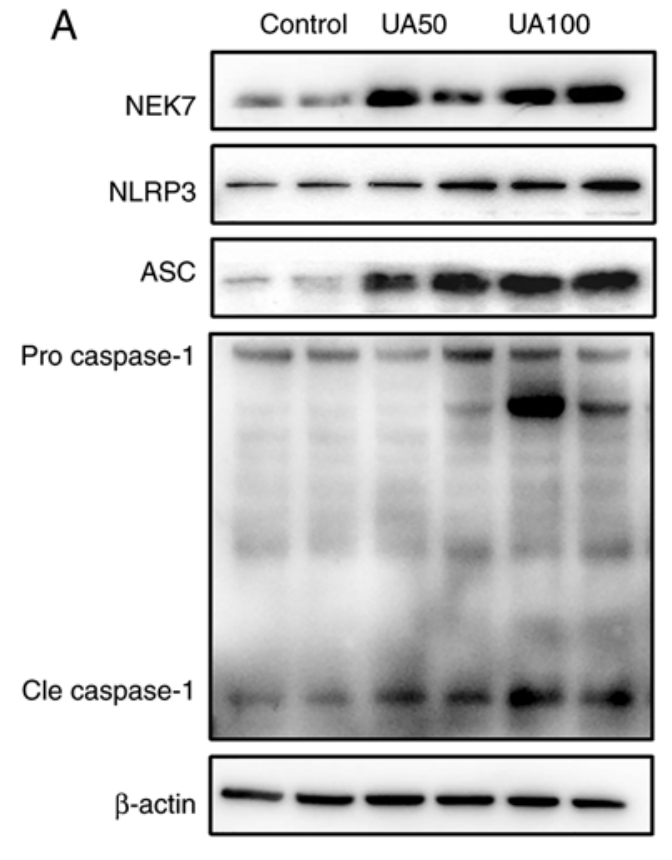

B
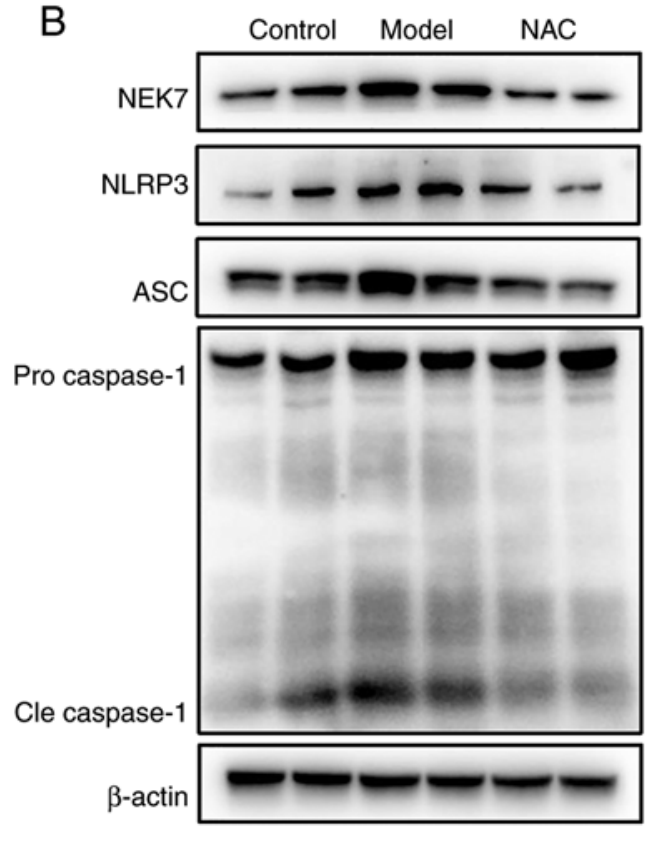
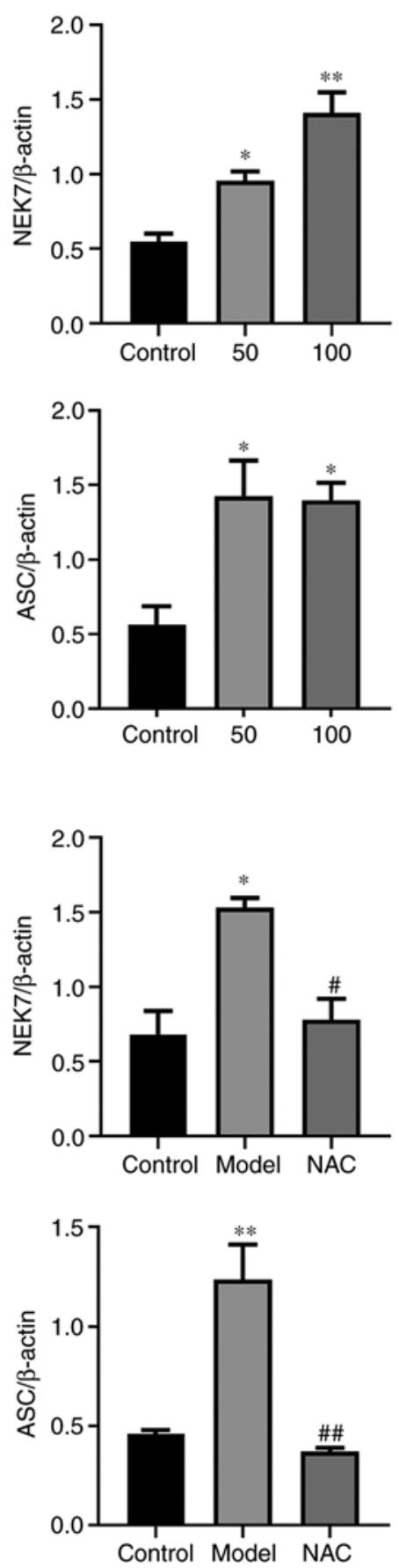
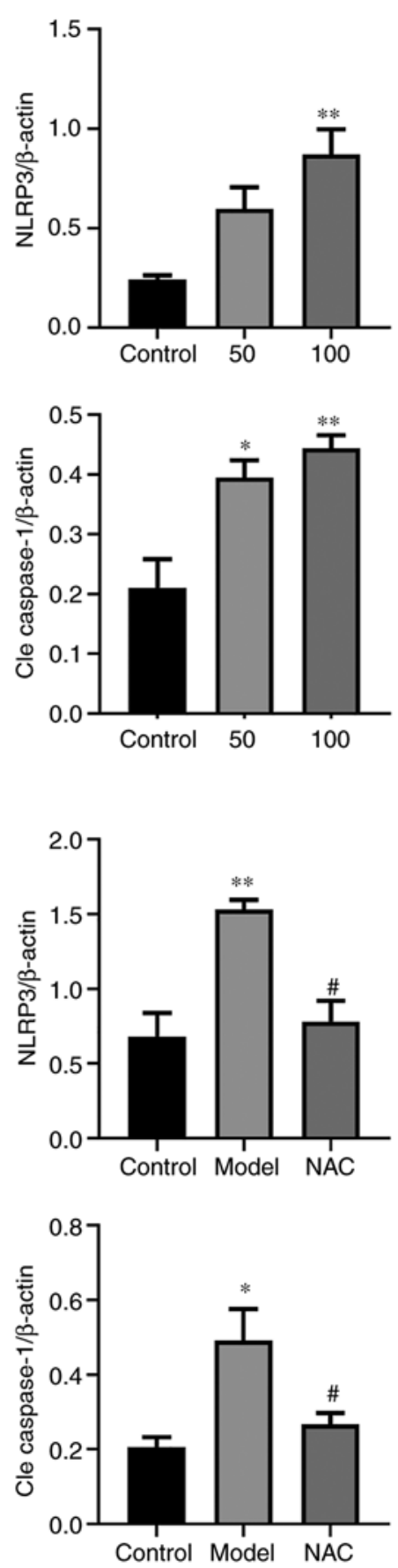

Figure 3. Effects of UA on the apoptotic pathway in injured NRK-52E cells. (A and B) Levels of apoptotic pathway proteins (NEK7, NLRP3, ASC and caspase-1) in response to UA $(0,50$ and $100 \mu \mathrm{g} / \mathrm{ml})$ treatment of NRK-52E cells, as assessed using western blotting. NRK-52E cells were pretreated with $20 \mathrm{mM} \mathrm{NAC}$ for $1 \mathrm{~h}$ and then treated with $100 \mu \mathrm{g} / \mathrm{ml}$ UA for an additional $24 \mathrm{~h}$ and the levels of NEK7, NLRP3, ASC and caspase-1 were determined. Data represent the mean \pm standard error of the mean; $n=4$ independent samples repeated three times. ${ }^{*} \mathrm{P}<0.05,{ }^{* *} \mathrm{P}<0.01$ vs. the control group. ${ }^{\prime \prime} \mathrm{P}<0.05$, ${ }^{\# \#} \mathrm{P}<0.01$ vs. the model group. UA, uric acid; NAC, N-acetyl-1-cysteine; NEK7, Never in mitosis gene A-related kinase 7; NLRP3, NLR family pyrin domain containing 3; ASC, apoptosis-associated speck-like; Cle, cleaved.

peroxidase-labeled goat anti-mouse $\operatorname{IgG}(\mathrm{H}+\mathrm{L}$; cat. no. A0216; 1:1,000; ) and horseradish peroxidase-labeled goat anti-rabbit IgG (H+L; cat. no. A0208; 1:1,000;) were purchased from Beyotime Institute of Biotechnology.

Flow cytometry detection of ROS. Detection of intracellular ROS in NRK-52E cells: Following treatment, cells were washed twice in PBS and incubated with $0.1 \%$ 2',7'-dichlorofluorescin diacetate (DCFH-DA; cat. no. E004-1-1; Nanjing Jiancheng
Bioengineering Institute) as a probe at $37^{\circ} \mathrm{C}$ for $60 \mathrm{~min}$. Subsequently, the cells were digested with $0.25 \%$ trypsin. After being centrifuged at $55.5 \mathrm{x}$ g for $5 \mathrm{~min}$, the cells were resuspended in $400 \mu \mathrm{l}$ of $1 \mathrm{X}$ binding buffer and then subjected to flow cytometry using a BD FACSCalibur flow cytometer (BD Biosciences). The excitation wavelength was $500(500 \pm 15 \mathrm{~nm})$ and the emission wavelength was $525(530 \pm 20 \mathrm{~nm})$. The results were expressed as fluorescence values. FlowJo software was used for analysis of data (v10; FlowJo LLC). 
A

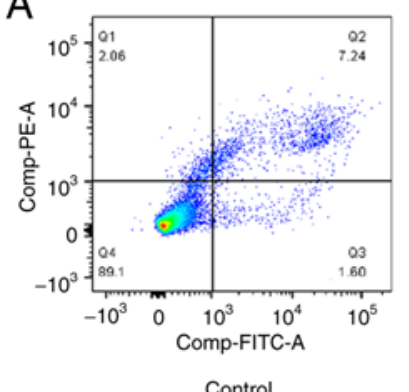

B

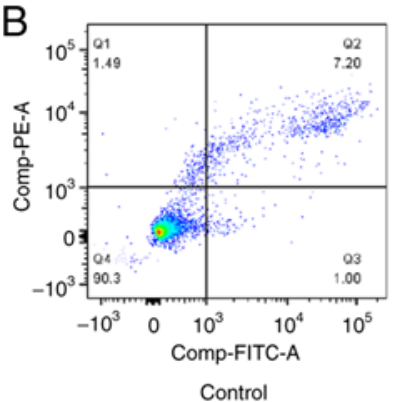

C

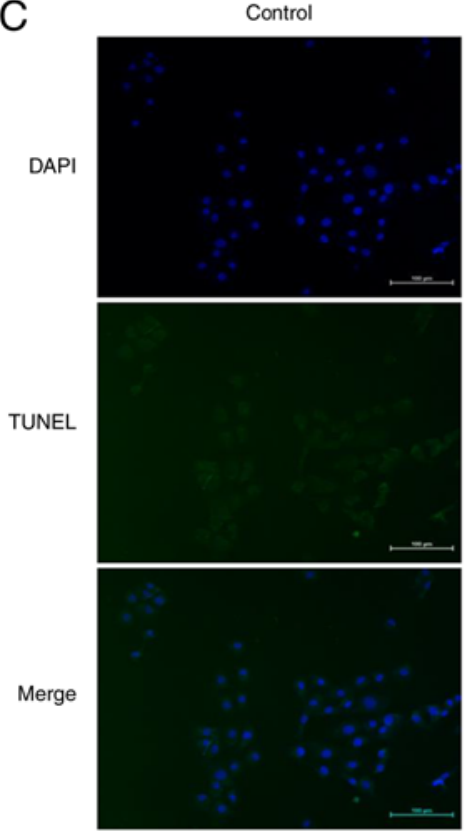

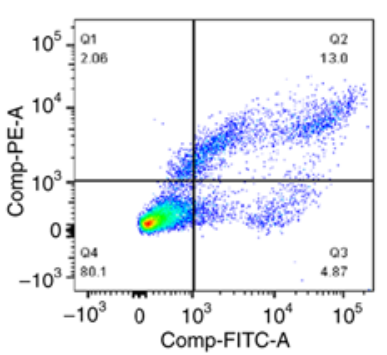

UA50

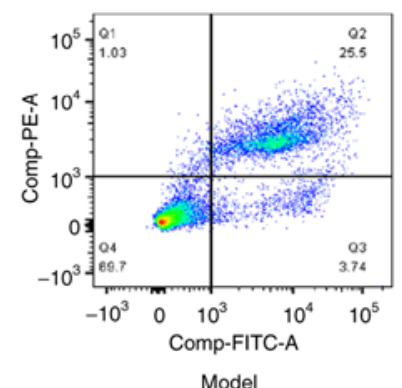

Model

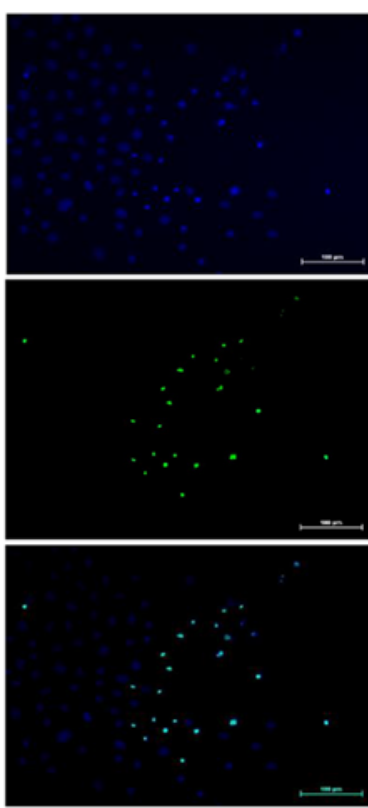

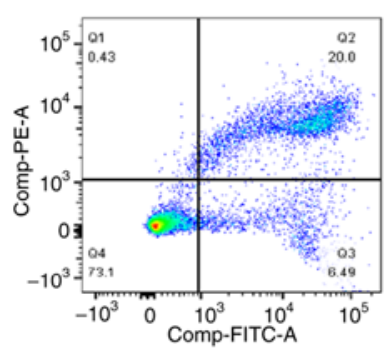

UA100

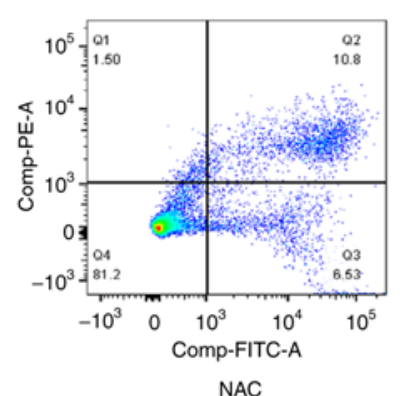

NAC

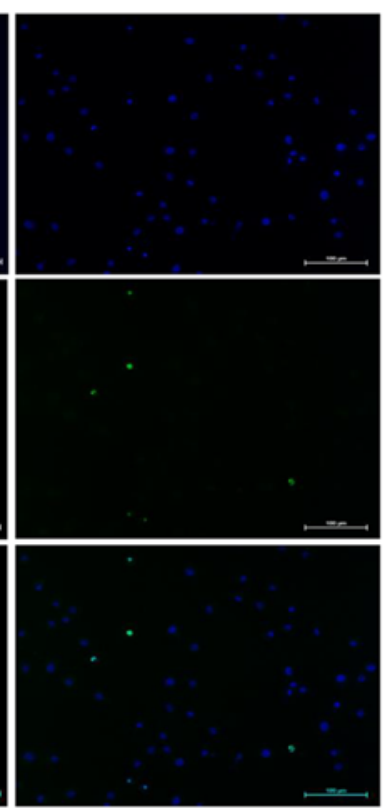

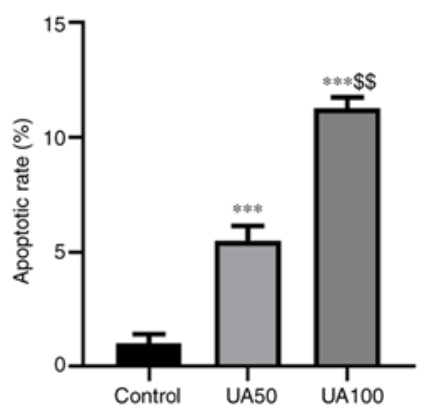
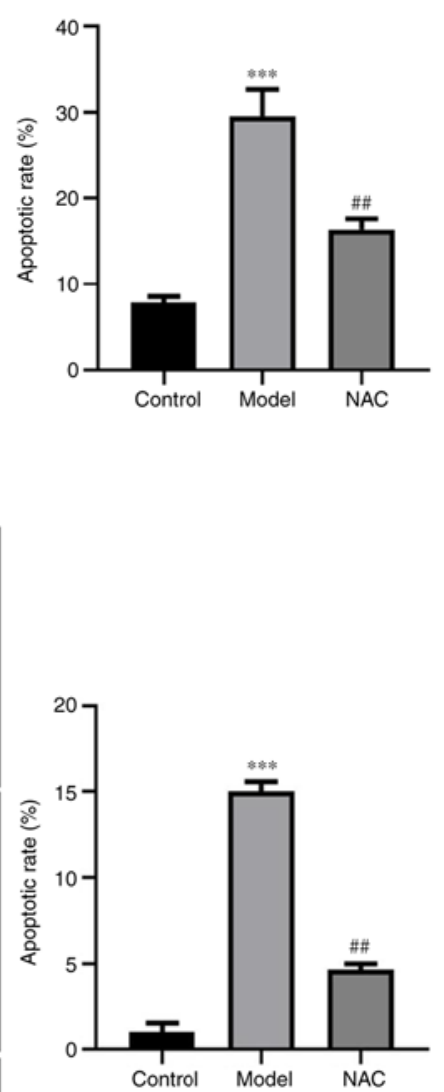

Figure 4. Effects of UA on the apoptosis of NRK-52E cells. (A) Flow cytometry assays showing apoptosis of NRK-52E cells treated with 0,50 and $100 \mu$ g/ml $\mathrm{UA}$ for $24 \mathrm{~h}$ and the percentage of apoptotic cells. (B) NRK-52E cells were pretreated with $20 \mathrm{mM}$ NAC for $1 \mathrm{~h}$ and then treated with $100 \mu \mathrm{g} / \mathrm{ml} \mathrm{UA}$ for an additional $24 \mathrm{~h}$ and the percentage of apoptotic cells was examined using flow cytometry. (C) TUNEL assays were used to measure the UA-induced cell apoptosis (magnification, $\mathrm{x} 200$ ). Data represent the mean \pm standard error of the mean. ${ }^{* * *} \mathrm{P}<0.001 \mathrm{vs}$. the control group; ${ }^{\$ \$} \mathrm{P}<0.01 \mathrm{vs}$. the $\mathrm{UA} 50$ group; ${ }^{\# \#} \mathrm{P}<0.01$ vs. the model group. UA, uric acid; NAC, N-acetyl-1-cysteine.

Statistical analysis. Data are expressed as the mean \pm standard error of the mean. All statistical tests were performed using SPSS 21 software (IBM Corp.). Data were analyzed using an unpaired Student's t test; comparisons between groups involved one-way analysis of variance with Tukey-Kramer post-hoc test. Data were presented using GraphPad Prism 8 (GraphPad Software, Inc.). All the experiments were repeated three times for each experimental condition and the representative results are presented. $\mathrm{P}<0.05$ was considered to indicate a statistically significant difference.

\section{Results}

Effect of UA on morphological changes of NRK-52E cells. Initially, the CCK8 assay was performed to show that uric acid could inhibit the viability of NRK-52E cells when the concentration was $100 \mu \mathrm{g} / \mathrm{ml}$ UA for 24,48 and $72 \mathrm{~h}$ (Figs. S1-3). After statistical analysis, there was significant difference between the cells stimulated with $100 \mu \mathrm{g} / \mathrm{ml}$ uric acid for 24 and $48 \mathrm{~h}$ and normal cells, the results of $72 \mathrm{~h}$ showed that the cell survival rate of $100 \mu \mathrm{g} / \mathrm{ml}$ uric acid decreased significantly, 
A
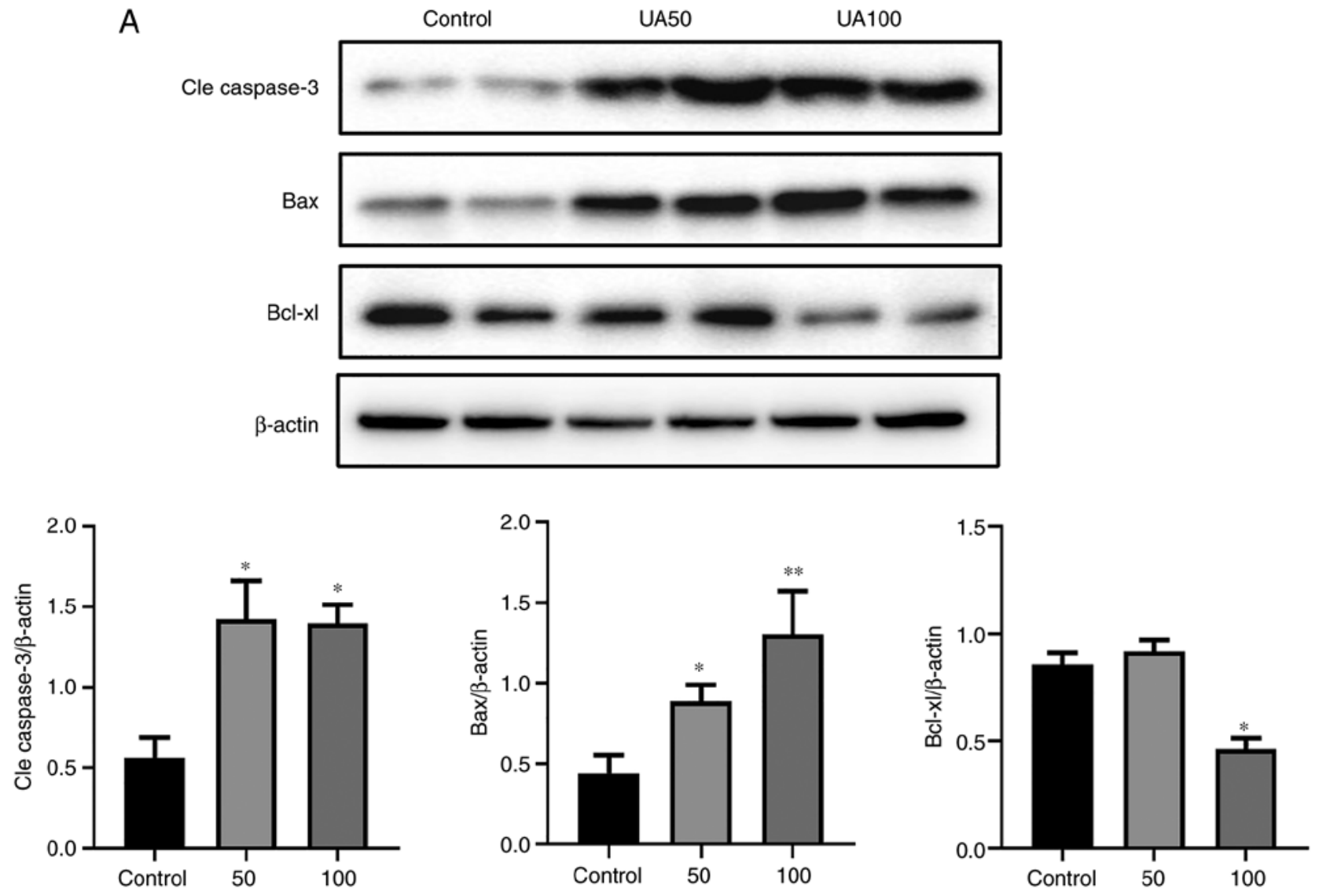

B
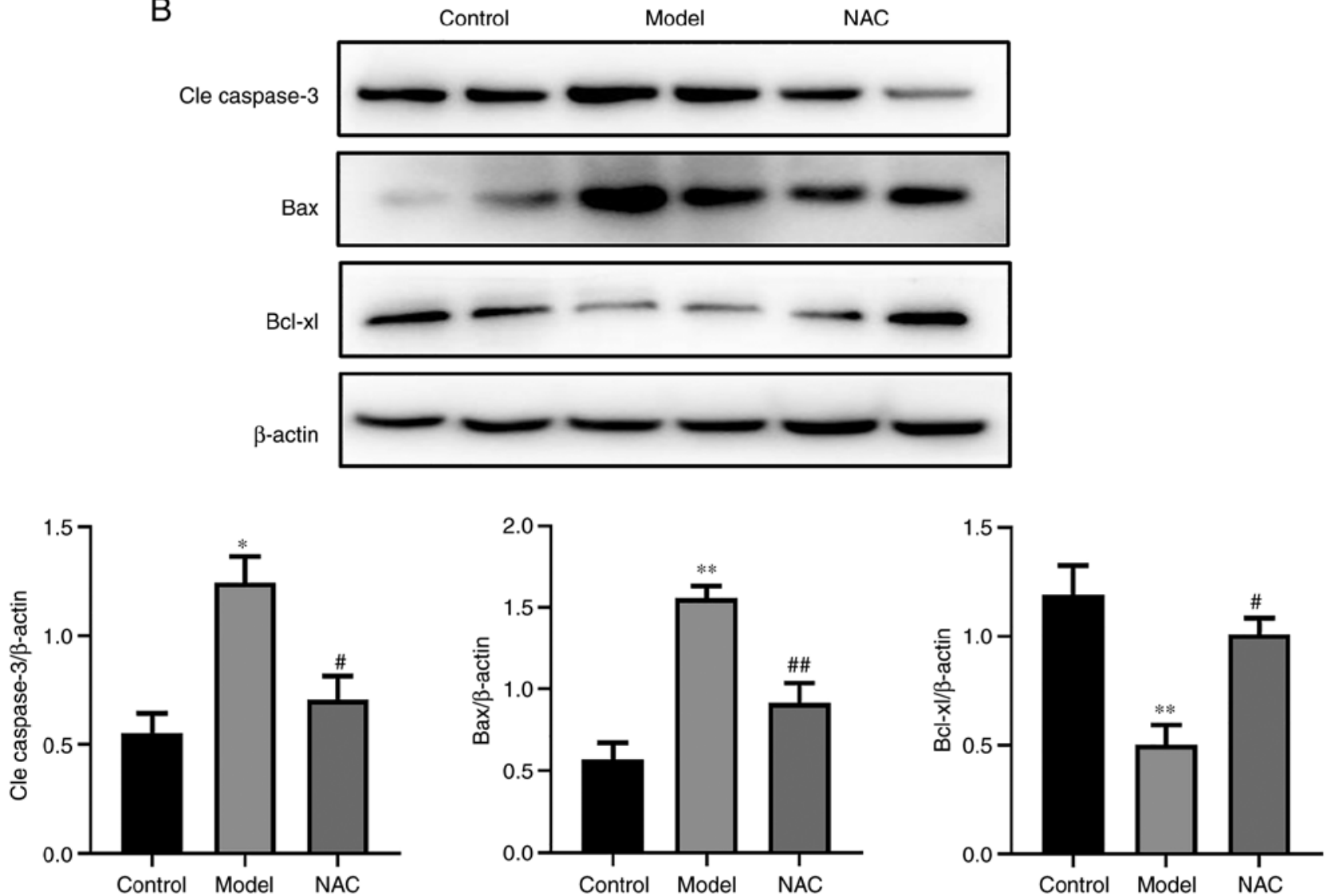

Figure 5. Effects of UA on the apoptotic proteins of NRK-52E cells during injury. (A) Levels of apoptotic proteins (Cle caspase-3, Bax and Bcl-xl) in response to UA $(0,50,100 \mu \mathrm{g} / \mathrm{ml})$ in NRK-52E cells subjected to injury, as assessed using western blotting. (B) NRK-52E cells were pretreated with $20 \mathrm{mM}$ NAC for $1 \mathrm{~h}$ and then treated with $100 \mu \mathrm{g} / \mathrm{ml}$ UA for an additional $24 \mathrm{~h}$ and the levels of Cle caspase-3, Bax and Bcl-xl were examined using western blotting. Data represent the mean \pm standard error of the mean; $\mathrm{n}=4$ independent samples and repeated three times. ${ }^{*} \mathrm{P}<0.05,{ }^{* *} \mathrm{P}<0.01$ vs. the control group; ${ }^{\#} \mathrm{P}<0.05$, ${ }^{\# \#} \mathrm{P}<0.05$ vs. the model group. UA, uric acid; NAC, N-acetyl-1-cysteine; Cle, cleaved. 
which could not meet the requirements of the experiment (data not shown). Combined with this study, the effect of early uric acid levels on NRK-52E cells was mainly observed, hence, $100 \mu \mathrm{g} / \mathrm{ml}$ UA was selected to stimulate NRK-52E cells $24 \mathrm{~h}$ in the following assay (data not shown). The morphological changes of NRK-52E cells were observed after $24 \mathrm{~h}$ of treatment with UA. NRK-52E cells appeared pebble shaped in the control group (Fig. 1); however, following treatment with 50 and $100 \mu \mathrm{g} / \mathrm{ml} \mathrm{UA}$ for $24 \mathrm{~h}$, the cells became progressively swollen, the membrane ruptured and became detached (Fig. 1). In addition, the cell adhesion ability was weakened and the distribution density of the cells was reduced significantly.

Effect of UA on ROS production in NRK-52E cells. As shown in Fig. 2A and C, treating NRK-52E cells with 50 and $100 \mu \mathrm{g} / \mathrm{ml}$ UA for $24 \mathrm{~h}$ significantly increased ROS levels compared with those in the control group. To further assess whether NAC inhibited the UA-induced increase in ROS levels, NRK-52E cells were pretreated with NAC for $1 \mathrm{~h}$; and then the cells were co-cultured with UA for $24 \mathrm{~h}$. As expected, the number of DCFH-DA-positive cells was increased by UA treatment compared with that in the NAC group (Fig. 2B and C). Thus, pretreatment with NAC significantly inhibited the UA-induced increase in ROS levels.

Effect of UA on the NEK7-NLRP3 signaling pathway activation. The present study evaluated the effects of 50 and $100 \mu \mathrm{g} / \mathrm{ml}$ UA on the NEK7-NLRP3 signaling pathway. Fig. 3A shows that UA upregulated the levels of NEK7, NLRP3, ASC and Cleaved-caspase-1 in a dose-dependent manner. Compared with that in the $100 \mu \mathrm{g} / \mathrm{ml}$ UA group, NAC attenuated the effect of UA on the levels of NEK7, NLRP3, ASC and Cleaved-caspase-1 (Fig. 3B).

Effect of UA on NRK-52E cell apoptosis. To evaluate UA-induced apoptosis of NRK-52E cells following treatment with UA, the apoptosis rate was detected using flow cytometry and TUNEL assays. The results showed that UA significantly promoted apoptosis of NRK-52E cells compared with the non-treated control group (Fig. 4A-C). Flow cytometry analysis showed that the number of $\mathrm{FITC}^{+}$and $\mathrm{PI}^{-}$cells increased following UA treatment. The ratio of $\mathrm{FITC}^{+}$and $\mathrm{PI}^{+}$cells was higher compared with the control group, indicating that the cells exhibited advanced apoptosis or necrosis. Treatment with NAC abrogated the increases in cell apoptosis induced by UA compared with that in cells treated with UA alone (Fig. 4B and C). In addition, the levels of apoptosis markers (Cleaved-caspase-3, Bcl-xl and Bax) were also assessed via western blotting. As shown in Fig. 5A, UA decreased the expression of Bcl-xl and increased the expression levels of Bax and Cleaved-caspase-3 in a dose-dependent manner in NRK-52E cells. NAC attenuated the effect of UA on the levels of these proteins (Fig. 5B).

\section{Discussion}

Hyperuricemia has been widely reported as a risk factor for a variety of kidney diseases $(14,15)$. The observation that hyperuricemia frequently precedes the development of CKD suggests that factors other than renal insufficiency are likely involved in the pathogenesis of the elevation in uric acid (16). Studies have confirmed that $2 / 3$ of UA in the human body is reabsorbed and secreted by the renal tubules $(17,18)$. Therefore, renal tubular epithelial cell injury might be an important factor in the renal damage caused by UA (19). High levels of $\mathrm{UA}$, as a dangerous molecular model, are ingested into the cell lysosome, increase the permeability of lysosomal membrane. Lysosomal membrane permeabilization results in translocation to the cytoplasm of the intraluminal contents, followed by the release of cathepsins into the cytosol. Specific cathepsins are released from the permeabilized lysosomes resulting in mitochondrial damage, mitochondria is an important place for cells to produce ROS $(20,21)$. Abnormal function and structure of mitochondrial respiratory chain can cause electron leakage and produce a large amount of ROS. Oxidative stress plays an important role in renal apoptosis; ROS generated by mitochondria after the binding of UA crystals to TLR is a pivotal mediator for activation of the NLRP3 inflammasome in the development of MSU-crystal-induced renal inflammation (22). The current study revealed that oxidative stress generated by UA crystals induced renal apoptosis through activation of a caspase-dependent apoptosis pathway (23). A previous study demonstrated that UA at a concentration of $10 \mathrm{mg} / \mathrm{dl}$ activates NALP3 and increases cleaved caspase-1 level and caspase-1 activity. Glyburide, a NALP3 inhibitor, prevents the above almost completely (24). In the present study, when the stimulation time of UA was fixed, the cell survival rate gradually decreased with the increase of the stimulation concentration and the damage of UA to cells increased with the increase of the stimulation concentration. In addition, the relevant literature was consulted, so $100 \mu \mathrm{g} / \mathrm{ml} \mathrm{UA}$ for $24 \mathrm{~h}$, and not 48 or $72 \mathrm{~h}$, was used as the timepoint (23). It was found that UA promoted dose-dependent apoptotic damage in NRK-52E cells over $24 \mathrm{~h}$. The results of the present study demonstrated a dose-dependent increase in cell apoptosis upon UA treatment. It showed that NEK7/NLRP3 signaling might be involved in the mechanism of tubular epithelial cells apoptosis in a high UA environment. More significantly, ROS, which is a key factor in the process of apoptosis, was associated closely with tubular epithelial cells injury and thus might represent a direct mechanism of UA-induced tubular epithelial cell apoptosis.

Cell death mechanisms have been proven to be associated with the development of UA-induced kidney disease (25). High apoptosis rates have been observed in the renal tubular epithelial cells of rats with UA-induced kidney disease (26). Increasing evidence shows that apoptosis could serve as a therapeutic paradigm in hyperuricemia (27). Yang et al (28) found that renal tubular epithelial cell apoptosis occurs in rats with UA-induced kidney disease and the use of the antioxidant glutathione can inhibit cell apoptosis significantly and reduce kidney damage. The results of the present study also indicated that NAC inhibited UA-induced apoptosis. In addition, the levels of the proapoptotic factors cleaved caspase-3 and Bax were upregulated significantly and the level of antiapoptotic factor Bcl-xl was downregulated after stimulation with UA. NAC attenuated the effect of UA on the levels of these proteins.

Previous studies demonstrated that various stress stimuli, including the oxidative stress caused by ROS, might induce the activation of NLRP3 inflammasome signaling pathways $(29,30)$. In addition, NLRP3 inflammasome activation 
contributes to stress-induced apoptosis (31). NLRP3 inflammasomes can also activate caspase- 8 and activated caspase- 8 promoted caspase- 3 cleavage in response to nigericin, which initiates apoptosis (32). Tsuchiya et al (33) reported that caspase-1 induction of apoptosis involves the Bid-dependent mitochondrial apoptosis pathway. NEK7 is a key protein in the assembly and activation of NLRP3 inflammasomes (34). In the downstream pathway of mitochondrial ROS production, NEK7 binds to the NLRP3 leucine rich repeat region in a kinase-independent manner. NEK7 mediates the activation of NLRP3 inflammasomes by connecting adjacent NLRP3 subunits through a biphasic interaction (13). In a Nek7 knockout mouse model, the absence of NEK7 inhibits NLRP3 activation, which verifies the key role of NEK7 in the assembly and activation of NLRP3 (35). The results of the present study demonstrated that ROS upregulated the levels of NEK7, NLRP3, ASC and caspase-1. NAC was also observed to inhibit NEK7/NLRP3 activation, suggesting that NAC attenuated renal tubular epithelial cell apoptosis by reducing UA-induced oxidative stress via the NEK7/NLRP3 signaling pathway. ROS-mediated activation of NLRP3 inflammatory bodies appeared to be related to NEK7. A previous study demonstrated that artemisinin can regulate NEK7-mediated NLRP3 inflammasome activation by suppressing the interaction between NEK7 and NLRP3 in lipopolysaccharide and UA-induced inflammation in human U937 macrophages and in UA-induced arthritic mice (36). Thus, inhibition of NEK7/NLRP3 activation reduced UA-induced renal tubular cell damage.

Oxidative stress in tubular cells has emerged as a major cause of renal damage in different pathophysiological processes, such as UA-induced kidney disease and diabetic nephropathy $(23,37)$. ROS are considered to be important mediators of several biological responses, such as inflammation and apoptosis $(38,39)$. ROS is a normal metabolite of redox reactions. The normal balance of ROS can bidirectionally regulate cell apoptosis and proliferation and activates a series of signal transduction pathways essential for transcription (40). Excessive ROS can damage cell integrity and lead to tissue dysfunction through lipid, protein, mitochondria and cellular DNA peroxidation (22). The present study demonstrated that oxidative stress generated by UA activated a specific proteases termed the executioner caspases (e.g., cleaved caspase-3) and downregulated the expression of the anti-apoptotic molecule $\mathrm{Bcl}-\mathrm{xl}$ in the caspase-dependent apoptosis pathway. Recent studies indicate that UA triggers the generation of oxidant stress in several different cell types (41-43). In early chronic kidney disease, UA can increase the production of ROS, regulate the activation of the NLRP3 inflammasome and further induce early vascular endothelial cell injury of chronic kidney disease (5). Oxidative stress injury is also reported to be involved in UA-induced pancreatic cell apoptosis (44). The present study showed that UA increased the production of ROS in a dose-dependent manner. Subsequently, it was confirmed that the apoptotic events in NRK-52E cells cultivated under high UA levels were dependent on ROS generation. Inhibition of ROS has been demonstrated as protective in several experimental cell models, such as hypoxia reoxygenation, unilateral ureteral obstruction (UUO), chronic renal failure and diabetic nephropathy (45-48). The findings of the present study offered an explanation for the renal cell protective effects of ROS scavengers. It was observed that UA-induced ROS production was inhibited by the antioxidant NAC, suggesting a major role of UA in inducing oxidative stress in renal tubular epithelial cell injury.

Accumulating evidence demonstrates that the intake of toxic agents (such as uric acid, oxalic acid and heavy metals) might lead to cell antioxidant defense dysfunction and apoptosis (49-51); however, the exact mechanism of apoptosis caused by UA-induced antioxidant imbalance requires further study. There have been a number of studies on the mechanism of UA-mediated ROS-induced apoptosis. It is reported that the ROS-p53 signaling pathway is involved in the pathogenesis of UA kidney injury. Li et al (11) observe that UA promotes ROS-induced apoptosis in HK-2 cells. The mechanism involves the activation of P38 and ERK1/2. The present study verified the role of NEK7 in UA-induced apoptosis of renal tubular cells. However, it only verified the role of NEK7 in ROS-activated, NLRP3-induced apoptosis and did not use NLRP3 inhibitors and NEK7 knockdown; this is the limitation of the present study. Thus, further research is required to understand the mechanism by which UA stimulates ROS to influence NEK7-induced NLRP3 inflammasome activation and apoptosis. Hence, the exact mechanisms and inhibitors of NEK7-licensed NLRP3 inflammasome activation should be investigated further, NLRP3 inhibitors and NEK7 knockout should be further investigated. Therefore, the results of the present study suggested that the ROS-NEK7-NLRP3 signaling pathway might be one of the main mechanisms through which UA causes renal tubular epithelial cell apoptosis. However, there might be other mechanisms by which UA induces apoptosis and a study reports that inhibition of EZH2 attenuates renal tubular cell apoptosis in hyperuricemic mice (52), thus further experiments are needed.

In summary, ROS can lead to the apoptosis of NRK-52E cells, which might be an important pathogenic characteristic of renal tubular damage caused by UA. The upregulation of cleaved caspase-3 and Bax, the downregulation of Bcl-xl levels and the activation of the NEK7-NLRP3 signaling pathway might serve key roles in the apoptosis of NRK-52E cells induced by ROS.

\section{Acknowledgements}

Not applicable.

\section{Funding}

The present study was supported by the National Natural Science Foundation of China (grant nos. 81874437 and 81904126), the Three Year Action Plan Project of Shanghai Accelerating Development of Traditional Chinese Medicine [grant no. ZY (2018-2020)-CCCX-2003-08] and the Key Disciplines Group Construction Project of Pudong Health Bureau of Shanghai (grant no. PWZxq2017-07).

\section{Availability of data and materials}

The datasets used and/or analyzed during the current study are available from the corresponding author on reasonable request. 


\section{Authors' contributions}

DL and JG conceived and designed the study. DL wrote the manuscript. LW, JO, LL, CW and JZ performed the experiments; LL and YW analyzed the data; JG reviewed and revised the manuscript. DL and JG confirm the authenticity of all the raw data. All authors have read and approved the final manuscript.

\section{Ethics approval and consent to participate}

Not applicable.

\section{Patient consent for publication}

Not applicable.

\section{Competing interests}

The authors declare that they have no competing interests.

\section{References}

1. He L, Fan Y, Xiao W, Chen T, Wen J, Dong Y, Wang Y, Li S, Xue R, Zheng L, et al: Febuxostat attenuates ER stress mediated kidney injury in a rat model of hyperuricemic nephropathy. Oncotarget 8: 111295-111308, 2017.

2. Kang DH: Hyperuricemia and progression of chronic kidney disease: Role of phenotype transition of renal tubular and endothelial cells. Contrib Nephrol 192: 48-55, 2018.

3. Tao M, Shi Y, Tang L, Wang Y, Fang L, Jiang W, Lin T, Qiu A, Zhuang S and Liu N: Blockade of ERK1/2 by U0126 alleviates uric acid-induced EMT and tubular cell injury in rats with hyperuricemic nephropathy. Am J Physiol Renal Physiol 316 F660-F673, 2019.

4. Priante G, Gianesello L, Ceol M, Del Prete D and Anglani F: Cell death in the kidney. Int J Mol Sci 20: 3598, 2019.

5. Yin W, Zhou QL, OuYang SX, Chen Y, Gong YT and Liang YM: Uric acid regulates NLRP3/IL-1 $\beta$ signaling pathway and further induces vascular endothelial cells injury in early CKD through ROS activation and $\mathrm{K}^{+}$efflux. BMC Nephrol 20: 319, 2019.

6. Moreno-Irusta A, Dominguez EM, Marín-Briggiler CI, Matamoros-Volante A, Lucchesi O, Tomes CN, Treviño CL, Mariano GB, Lascano R, Losinno L and Giojalas LC: Reactive oxygen species are involved in the signaling of equine sperm chemotaxis. Reproduction 159: 423-436, 2020.

7. Liu G, Chen X, Wang Q and Yuan L: NEK7: A potential therapy target for NLRP3-related diseases. Biosci Trends 14: 74-82, 2020.

8. Shi H, Wang Y, Li X, Zhan X, Tang M, Fina M, Su L, Pratt D, $\mathrm{Bu} \mathrm{CH}$, Hildebrand $\mathrm{S}$, et al: NLRP3 activation and mitosis are mutually exclusive events coordinated by NEK7, a new inflammasome component. Nat Immunol 17: 250-258, 2016.

9. Ma ZZ, Sun HS, Lv JC, Guo L and Yang QR: Expression and clinical significance of the NEK7-NLRP3 inflammasome signaling pathway in patients with systemic lupus erythematosus. J Inflamm (Lond) 15: 16, 2018.

10. Braga TT, Forni MF, Correa-Costa M, Ramos RN, Barbuto JA, Branco P, Castoldi A, Hiyane ML, Davanso MR, Latz E, et al: Soluble uric acid activates the NLRP3 inflammasome. Sci Rep 7: 39884, 2017.

11. Li Z, Sheng Y, Liu C, Li K, Huang X, Huang J and Xu K: Nox4 has a crucial role in uric acid-induced oxidative stress and apoptosis in renal tubular cells. Mol Med Rep 13: 4343-4348, 2016.

12. Wu Y, He F, Li Y, Wang H, Shi L, Wang Q, Ou J, Zhang X, Huang D, Xu L, et al: Effects of Shizhifang on NLRP3 inflammasome activation and renal tubular injury in hyperuricemic rats. Evid Based Complement Alternat Med 2017: 7674240, 2017

13. Sharif H, Wang L, Wang WL, Magupalli VG, Andreeva L, Qiao Q, Hauenstein AV, Wu Z, Núñez G, Mao Y and Wu H: Structural mechanism for NEK7-licensed activation of NLRP3 inflammasome. Nature 570: 338-343, 2019.
14. Oh TR, Choi HS, Kim CS, Bae EH, Ma SK, Sung SA, Kim YS, $\mathrm{Oh} \mathrm{KH,} \mathrm{Ahn} \mathrm{C} \mathrm{and} \mathrm{Kim} \mathrm{SW:} \mathrm{Hyperuricemia} \mathrm{has} \mathrm{increased} \mathrm{the}$ risk of progression of chronic kidney disease: Propensity score matching analysis from the KNOW-CKD study. Sci Rep 9: 6681, 2019.

15. Han Y, Xu X, Tang C, Gao P, Chen X, Xiong X, Yang M, Yang S, Zhu X, Yuan S, et al: Reactive oxygen species promote tubular injury in diabetic nephropathy: The role of the mitochondrial ros-txnip-nlrp3 biological axis. Redox Biol 16: 32-46, 2018.

16. Wu YY, Qiu XH, Ye Y, Gao C, Wu F and Xia G: Risk factors analysis for hyperuricemic nephropathy among CKD stages 3-4 patients: An epidemiological study of hyperuricemia in CKD stages 3-4 patients in Ningbo, China. Ren Fail 40: 666-671, 2018.

17. Hyndman D, Liu S and Miner JN: Urate handling in the human body. Curr Rheumatol Rep 18: 34, 2016.

18. Jung SW, Kim SM, Kim YG, Lee SH and Moon JY: Uric acid and inflammation in kidney disease. Am J Physiol Renal Physiol 318: F1327-F1340, 2020.

19. Xiao J, Zhang X, Fu C, Yang Q, Xie Y, Zhang Z and Ye Z: Impaired $\mathrm{Na}^{+}-\mathrm{K}^{+}$-ATPase signaling in renal proximal tubule contributes to hyperuricemia-induced renal tubular injury. Exp Mol Med 50: e452, 2018.

20. Isaka Y, Takabatake Y, Takahashi A, Saitoh T and Yoshimori T: Hyperuricemia-induced inflammasome and kidney diseases. Nephrol Dial Transplant 31: 890-896, 2016.

21. Wang F, Gomez-Sintes R and Boya P: Lysosomal membrane permeabilization and cell death. Traffic 19: 918-931, 2018.

22. Zhou R, Yazdi AS, Menu P and Tschopp J: A role for mitochondria in NLRP3 inflammasome activation. Nature 469: 221-225, 2011.

23. Choe JY, Park KY and Kim SK: Oxidative stress by monosodium urate crystals promotes renal cell apoptosis through mitochondrial caspase-dependent pathway in human embryonic kidney 293 cells: Mechanism for urate-induced nephropathy. Apoptosis 20: 38-49, 2015.

24. Eleftheriadis T, Pissas G, Antoniadi G, Makri P, Liakopoulos V and Stefanidis I: Urate crystals induce NLRP3 inflammasome-dependent IL-1 $\beta$ secretion and proliferation in isolated primary human T-cells. Hippokratia 19: 41-46, 2015.

25. Shi Y, Tao M, Ma X, Hu Y, Huang G, Qiu A, Zhuang S and Liu N: Delayed treatment with an autophagy inhibitor 3-MA alleviates the progression of hyperuricemic nephropathy. Cell Death Dis 11: 467, 2020.

26. $\mathrm{Hu}$ J, Yang $\mathrm{Z}$, Wu $\mathrm{H}$ and Wang D: Rhein attenuates renal inflammatory injury of uric acid nephropathy via lincRNA-Cox $2 / \mathrm{miR}-150-5 \mathrm{p} / \mathrm{STAT} 1$ axis. Int Immunopharmacol 85: 106620, 2020.

27. He Y, Qu Q, Luo T, Gong Y, Hou Z, Deng J, Xu Y, Wang B and Hao S: Human hair keratin hydrogels alleviate rebleeding after intracerebral hemorrhage in a rat model. ACS Biomater Sci Eng 5: 1113-1122, 2019.

28. Yang L, Chang B, Guo Y, Wu X and Liu L: The role of oxidative stress-mediated apoptosis in the pathogenesis of uric acid nephropathy. Ren Fail 41: 616-622, 2019.

29. Zhang Y, Liu L, Sun D, He Y, Jiang Y, Cheng KW and Chen F: DHA protects against monosodium urate-induced inflammation through modulation of oxidative stress. Food Funct 10: 4010-4021, 2019.

30. Wang M, Zhao J, Zhang N and Chen J: Astilbin improves potassium oxonate-induced hyperuricemia and kidney injury through regulating oxidative stress and inflammation response in mice. Biomed Pharmacother 83: 975-988, 2016.

31. Sun L, Ma W, Gao W, Xing Y, Chen L, Xia Z, Zhang Z and Dai Z: Propofol directly induces caspase-1-dependent macrophage pyroptosis through the NLRP3-ASC inflammasome. Cell Death Dis 10: 542, 2019.

32. Gaidt MM, Ebert TS, Chauhan D, Ramshorn K, Pinci F, Zuber S, O'Duill F, Schmid-Burgk JL, Hoss F, Buhmann R, et al: The DNA inflammasome in human myeloid cells is initiated by a STING-cell death program upstream of NLRP3. Cell 171: 1110-1124.e18, 2017

33. Tsuchiya $K$, Nakajima $S$, Hosojima $S$, Thi Nguyen D, Hattori $T$, Manh Le T, Hori O, Mahib MR, Yamaguchi Y, Miura M, et al: Caspase-1 initiates apoptosis in the absence of gasdermin D. Nat Commun 10: 2091, 2019.

34. Chiu HW, Li LH, Hsieh CY, Rao YK, Chen FH, Chen A, Ka SM and Hua KF: Glucosamine inhibits IL-1 $\beta$ expression by preserving mitochondrial integrity and disrupting assembly of the NLRP3 inflammasome. Sci Rep 9: 5603, 2019. 
35. Zeng Q, Deng H, Li Y, Fan T, Liu Y, Tang S, Wei W, Liu X, Guo X, Jiang J, et al: Berberine directly targets the NEK7 protein to block the NEK7-NLRP3 interaction and exert anti-inflammatory activity. J Med Chem 64: 768-781, 2021.

36. Kim SK, Choe JY and Park KY: Anti-inflammatory effect of artemisinin on uric acid-induced NLRP3 inflammasome activation through blocking interaction between NLRP3 and NEK7. Biochem Biophys Res Commun 517: 338-345, 2019.

37. Huang C, Zhang Y, Kelly DJ, Tan CY, Gill A, Cheng D, Braet F, Park JS, Sue CM, Pollock CA and Chen XM: Thioredoxin interacting protein (TXNIP) regulates tubular autophagy and mitophagy in diabetic nephropathy through the mTOR signaling pathway. Sci Rep 6: 29196, 2016.

38. Giribabu N, Karim K, Kilari EK and Salleh N: Phyllanthus niruri leaves aqueous extract improves kidney functions, ameliorates kidney oxidative stress, inflammation, fibrosis and apoptosis and enhances kidney cell proliferation in adult male rats with diabetes mellitus. J Ethnopharmacol 205: 123-137, 2017.

39. Zhang Y, Lv X, Hu Z, Ye X, Zheng X, Ding Y, Xie P and Liu Q: Protection of Mcc950 against high-glucose-induced human retinal endothelial cell dysfunction. Cell Death Dis 8: e2941-e2941, 2017

40. Zhou X, Bai C, Sun X, Gong X, Yang Y, Chen C, Shan G and Yao Q: Puerarin attenuates renal fibrosis by reducing oxidative stress induced-epithelial cell apoptosis via MAPK signal pathways in vivo and in vitro. Ren Fail 39: 423-431, 2017.

41. Cai W, Duan XM, Liu Y, Yu J, Tang YL, Liu ZL, Jiang S, Zhang CP, Liu JY and Xu JX: Uric acid induces endothelial dysfunction by activating the HMGB1/RAGE signaling pathway. Biomed Res Int 2017: 4391920, 2017.

42. Hong Q, Wang L, Huang Z, Feng Z, Cui S, Fu B, Cai G, Chen X and Wu D: High concentrations of uric acid and angiotensin II act additively to produce endothelial injury. Mediators Inflamm 2020: 8387654, 2020.

43. Zhang H, Ma Y, Cao R, Wang G, Li S, Cao Y, Zhang H, Liu M, Liu G, Zhang J, et al: Soluble uric acid induces myocardial damage through activating the NLRP3 inflammasome. J Cell Mol Med 24: 8849-8861, 2020.

44. Xin Y, Wang K, Jia Z, Xu T, Xu Q, Zahng C, Liu J, Chen R, Du $Z$ and Sun J: Zurampic protects pancreatic $\beta$-cells from high uric acid induced-damage by inhibiting URAT1 and inactivating the ROS/AMPK/ERK pathways. Cell Physiol Biochem 47: $1074-1083,2018$
45. Wang H, Peng X, Huang Y, Xiao Y, Wang Z and Zhan L: Propofol attenuates hypoxia/reoxygenation-induced apoptosis and autophagy in HK-2 cells by inhibiting JNK activation. Yonsei Med J 60: 1195-1202, 2019.

46. Sun L, Xu H, Wang Y, Ma X, Xu Y and Sun F: The mitochondrial-targeted peptide SBT-20 ameliorates inflammation and oxidative stress in chronic renal failure. Aging (Albany NY) 12: 18238-18250, 2020.

47. Jin JZ, Li HY, Jin J, Piao SG, Shen XH, Wu YL, Xu JC, Zhang LY, Jiang YJ, Zheng HL, et al: Exogenous pancreatic kininogenase protects against renal fibrosis in rat model of unilateral ureteral obstruction. Acta Pharmacol Sin 41: 1597-1608, 2020.

48. Shopit A,Niu M, Wang H, TangZ,Li X, Tesfaldet T, Ai J,Ahmad N, Al-Azab $M$ and Tang $\mathrm{Z}$ : Protection of diabetes-induced kidney injury by phosphocreatine via the regulation of ERK/Nrf2/HO-1 signaling pathway. Life Sci 242: 117248, 2020.

49. Han B, Li S, Lv Y, Yang D, Li J, Yang Q, Wu P, Lv Z and Zhang Z: Dietary melatonin attenuates chromium-induced lung injury via activating the Sirt1/Pgc-1 $\alpha / \mathrm{Nrf} 2$ pathway. Food Funct 10 : 5555-5565, 2019.

50. Yang D, Yang Q, Fu N, Li S, Han B, Liu Y, Tang Y, Guo XY, Lv Z and Zhang $\mathrm{Z}$ : Hexavalent chromium induced heart dysfunction via Sesn2-mediated impairment of mitochondrial function and energy supply. Chemosphere 264 (Pt 2): 128547, 2021.

51. Liu B, Yu H, Baiyun R, Lu J, Li S, Bing Q, Zhang X and Zhang Z: Protective effects of dietary luteolin against mercuric chloride-induced lung injury in mice: Involvement of AKT/Nrf2 and NF- $\kappa$ B pathways. Food Chem Toxicol 113: 296-302, 2018.

52. Shi Y, Xu L, Tao M, Fang L, Lu J, Gu H, Ma S, Lin T, Wang Y, Bao W, et al: Blockade of enhancer of zeste homolog 2 alleviates renal injury associated with hyperuricemia. Am J Physiol Renal Physiol 316: F488-F505, 2019. 